\title{
Tratamiento de COVID-19 en receptores de trasplante renal
}

\author{
COVID-19 treatment in kidney transplant recipients \\ Roxana Villca-Gonzales, * Luis Eduardo Morales-Buenrostro ${ }^{\ddagger}$ \\ * Servicio de Nefrología. Hospital Regional «Lic. Adolfo López Mateos». ISSSTE. \\ ₹ Área de Nefrología del Trasplante. Departamento de Nefrología y Metabolismo Mineral. \\ Instituto Nacional de Ciencias Médicas y Nutrición «Salvador Zubirán».
}

\begin{abstract}
RESUMEN
El presente artículo hace una revisión del tratamiento de COVID-19 en el contexto del paciente con trasplante renal. Por un lado, se discute el manejo de la inmunosupresión y por el otro lado, las terapias que hasta el momento se han publicado en relación al manejo de esta nueva enfermedad viral y sus complicaciones. La evidencia hasta el momento es limitada a series de casos o cohortes sin adecuados controles, con pocos ensayos clínicos, pero existen muchos estudios clínicos en curso, mejor diseñados, que podrían cambiar las conductas actuales de tratamiento en el corto plazo.
\end{abstract}

Palabras clave: SARS-CoV-2, COVID-19, tratamiento, trasplante renal, antivirales.

\section{INTRODUCCIÓN}

Desde diciembre de 2019 que se reportó un brote de neumonía atípica causada por un nuevo coronavirus, actualmente conocido como SARS-CoV-2, sabíamos del reto que enfrentaríamos ante la falta de tratamiento específico. A pesar de la experiencia de la epidemia de SARS-CoV en 2003 y de la epidemia de MERSCoV en 2012, también ocasionadas por Coronavirus, la realidad es que aún no contamos con tratamientos efectivos para este tipo de virus., ${ }^{1,2}$

Es bien sabido que los receptores de trasplante renal son un grupo poblacional de alto riesgo para desarrollar COVID-19 debido a la inmunosupresión crónica y a las comorbilidades coexistentes. Existen reportes

\section{ABSTRACT}

This article reviews COVID-19 treatment in the context of a kidney transplant patient. On the one hand, the management of immunosuppression is discussed, and on the other hand, the therapies that have been published so far in relation to the management of this new viral disease and its complications. The evidence so far is limited to case series or cohorts without adequate controls, with few clinical trials, but there are many better designed ongoing clinical studies that could change current treatment behaviors in the short term.

Keywords: SARS-CoV-2, COVID-19, treatment, kidney transplantation, antivirals.

que muestran que el cuadro clínico puede desarrollarse de forma atípica y progresar rápidamente a cuadros severos, implicando tasas de mortalidad de hasta el $30 \%$, muy por encima de la mortalidad reportada en la población general. ${ }^{1,2}$

En lo sucesivo nos enfocaremos a dos áreas del tratamiento integral del receptor de trasplante renal, en una primera parte, las conductas de manejo de la inmunosupresión y en una segunda parte, una revisión de las terapias utilizadas hasta el momento para el tratamiento de la enfermedad ocasionada por el virus SARS-CoV-2 denominada COVID-19. Por último, mostraremos las potenciales interacciones de los fármacos inmunosupresores con algunas de las terapias utilizadas, así como potenciales eventos adversos que 
habrá que tomar en cuenta a la hora de decidir el tratamiento. Cabe señalar que gran parte de las estrategias utilizadas actualmente para el tratamiento de la infección por SARS-CoV-2, parte de la evidencia tomada de las experiencias previas con SARS-CoV y MERSCoV o de la evidencia generada por estudios in vitro, otra parte es producto de estudios observacionales sin controles adecuados, mientras que los grandes ensayos clínicos bien diseñados apenas están saliendo a la luz o se encuentran en curso, por lo que debemos estar alerta a la nueva evidencia. ${ }^{3}$

\section{COVID-19 y manejo de la inmunosupresión}

Actualmente los fármacos de inmunosupresión se dividen en aquellos utilizados como «terapia de inducción» y aquellos que se utilizan de forma crónica para mantener la inmunosupresión a largo plazo o «terapia de mantenimiento».

\section{Terapia de inducción}

Actualmente disponemos de: 1) basiliximab, que es un anticuerpo monoclonal quimérico, dirigido contra el receptor de la interleucina 2; 2) timoglobulina, es un anticuerpo policlonal elaborado con extracto de timo que se inyecta a conejos, de donde se obtiene y después se purifica; 3) alemtuzumab, un anticuerpo monoclonal humanizado, dirigido contra la proteína CD52 que se encuentra en la superficie de los linfocitos $T$ y B. Con la timoglobulina y el alemtuzumab se produce una linfopenia prolongada en la subpoblación de linfocitos CD4, además de afectar otras líneas celulares, que comienzan desde el primer día de su aplicación y puede persistir suprimida por años, lo cual hace más susceptibles a quien los recibe para desarrollar infecciones. ${ }^{4}$ Por este motivo, la mayoría de grupos de trasplantes que mantienen actividad a pesar de la pandemia, evitan el uso de timoglobulina y alemtuzumab como terapias de inducción y en el tratamiento de rechazos celulares o sugieren tener precaución. ${ }^{1}$

\section{Terapia de mantenimiento}

Los esquemas de mantenimiento en trasplante renal, generalmente combinan tres medicamentos con diferente mecanismo de acción. La mayoría de ellos usan prednisona (excepto los esquemas libres de esteroides) combinado con otros dos medicamentos de grupos diferentes. El mejor esquema de prevención de rechazo agudo y por ende, el más utilizado en el mundo es: ta- crolimus, micofenolato de mofetilo/ácido micofenólico y prednisona. ${ }^{5}$ Sin embargo, los esquemas a base de belatacept ofrecen mejor función renal a largo plazo y mejor sobrevida del injerto a pesar de que pudieran tener mayor tasa de rechazo en el primer año. ${ }^{6}$ En los últimos años se ha demostrado que cualquier esquema con uso de inhibidores mTOR está asociado a mayor mortalidad y menor sobrevida del injerto, por lo que sólo se recomiendan en casos muy especiales. ${ }^{7}$

Respecto al manejo de inmunosupresión de mantenimiento durante la infección por SARS-CoV-2 ha sido muy heterogéneo, se realiza principalmente basado en opinión de expertos y traslapando la conducta que se toma frente a infecciones sistémicas graves. ${ }^{1,8-11} \mathrm{Al}$ inicio y ante la incertidumbre de cómo se comportaría en inmunosuprimidos, se llegó a suspender tanto el inhibidor de calcineurina como el antiproliferativo, pero pronto surgieron propuestas basadas en la gravedad de la enfermedad como el esquema que utilizamos en el Instituto Nacional de Ciencias Médicas y Nutrición «Salvador Zubirán», que se muestra en la Figura 1.10,12

El manejo de infecciones como virus BK, CMV, SARS-CoV, MERS, entre otros, nos han mostrado el beneficio de tener como primer paso la suspensión del antiproliferativo en casos moderados a graves, manteniendo el inhibidor de calcineurina, logrando reducir el número de rechazos comparado a la interrupción del inhibidor de calcineurina manteniendo el antiproliferativo. ${ }^{1}$ Pereira et al. ${ }^{13}$ reportaron a 90 pacientes con trasplante de órgano sólido con $\mathrm{CO}$ VID-19 en dos centros en Nueva York. El abordaje general fue disminuir o suspender los antiproliferativos mientras que la disminución de los otros agentes fue menos uniforme. El $76 \%$ se hospitalizaron, y de éstos, el $88 \%$ suspendieron los antiproliferativos, $18 \%$ inhibidores de calcineurina y $7 \%$ esteroides. La mortalidad global fue del $18 \%$ pero de los pacientes en terapia intensiva fue del $54 \%$.

Por otro lado, ciclosporina y tacrolimus inhiben la replicación in vitro del virus de hepatitis $\mathrm{C}$ (no in vivo) y del SARS-CoV, además de que ciclosporina es útil en el tratamiento de la linfohistiocitosis hemofagocítica cuya producción de citocinas es similar al síndrome de liberación de citocinas por COVID-19, de tal manera que la ciclosporina y el tacrolimus en dosis terapéuticas podrían inhibir la liberación de citocinas por COVID-19.14 Claro que en casos graves, con ventilación mecánica donde la presencia o el riesgo de coinfección bacteriana o micótica es alto, se deben suspender ambos, manteniendo sólo con esteroides hasta que se estabilice el paciente o se controle el foco infeccioso secundario. 
El belatacept, en un primer reporte de caso, se pensó que su uso podría tener un efecto mitigador de la respuesta inflamatoria de COVID-19 por su comportamiento benigno, ${ }^{15}$ sin embargo, poco después otro caso tuvo un comportamiento agresivo que descarta cualquier efecto protector. ${ }^{16}$

Dentro de los efectos adversos a nivel pulmonar de los inhibidores mTor (sirolimus y everolimus), están: neumonitis inducida por la droga y también neumopatía intersticial, por lo que se ha sugerido cambiarlos por inhibidor de calcineurina. ${ }^{17}$

Los esquemas libres de esteroide tampoco han mostrado algún beneficio. ${ }^{18}$ Cabe señalar que en aquellos que toman esteroides de mantenimiento (habitualmente $5 \mathrm{mg}$ de prednisona al día), se sugiere doblar la dosis de esteroide para evitar supresión adrenal en aquellos que requieren hospitalización. ${ }^{12} \mathrm{Si}$ bien más adelante se hablará de los efectos favorables del uso de dosis altas de dexametasona en manejo de COVID-19 en población no trasplantada, en el contexto de trasplantes no se sugiere hasta el momento dosis altas de esteroides por el temor a mayor replicación viral y sobreinfecciones, ${ }^{12}$ sin embargo, estas sugerencias fueron hechas previo a la nueva evidencia de la utilidad de dexametasona.

\section{Manejo del rechazo agudo en el contexto de COVID-19}

La reducción de inmunosupresión en los pacientes con COVID-19 lo pone en riesgo de desarrollar eventos de rechazo agudo o puede ser que aquellos con rechazo adquieran COVID-19, por ello, el manejo de la inmunosupresión debe valorarse caso por caso basado en su gravedad (Figura 1).10,12 El tratamiento de un rechazo en el contexto de COVID-19 también es un reto. Las dosis altas de esteroides en COVID-19 no habían mostrado utilidad y se temía su uso por el riesgo de incrementar la replicación del virus y potenciales eventos adversos como psicosis esteroidea, diabetes esteroidea, necrosis avascular de cadera, entre otros efectos adversos, ${ }^{19}$ aunque evidencia reciente señala el beneficio de dexametasona, lo cual se convierte en una buena opción, sólo cuidando el riesgo de sobreinfecciones bacterianas o
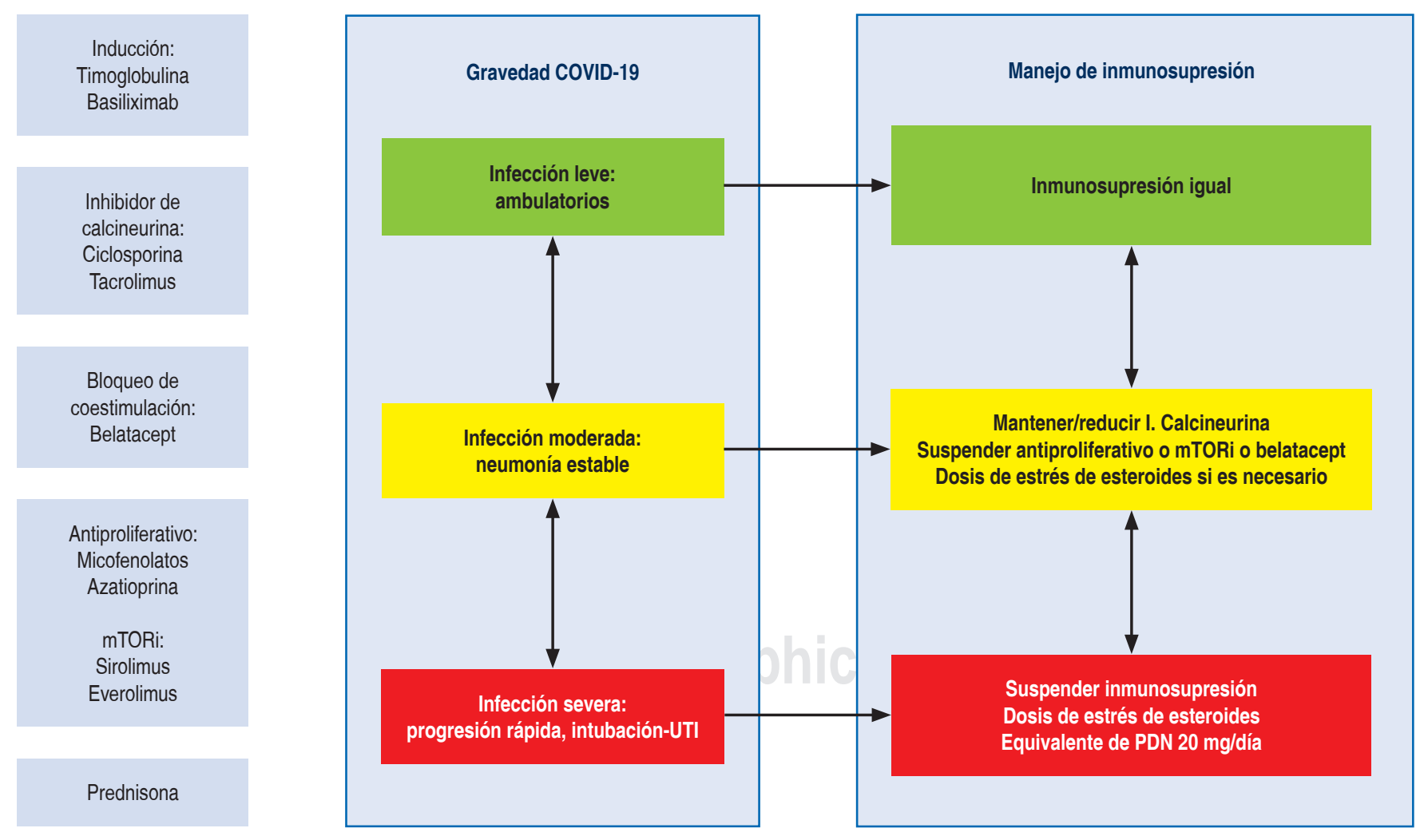

Figura 1: Manejo de inmunosupresión acorde al escenario clínico. 
micóticas. Si no responde a esteroides en el caso de rechazo celular, la sugerencia sería tratar de ajustar la inmunosupresión de base si la gravedad del caso lo permite, dado que el uso de timoglobulina se debe evitar. En el caso de rechazo humoral, se puede utilizar inmunoglobulina humana, que en reporte de series de casos ha demostrado potencial utilidad en COVID-19, así como previamente lo había mostrado en caso de MERS-CoV y SARS-CoV. ${ }^{12,20,21}$ El uso de plasmaféresis no pareciera tener impacto deletéreo siempre que la condición del paciente lo permita e incluso removería citocinas inflamatorias. Otras herramientas terapéuticas como rituximab no se sugieren por la depleción de linfocitos $B$ y se desconoce el impacto del uso de inhibidor de proteosomas, eculizumab e IdeS. Podría utilizarse tocilizumab cuyo uso se ha propuesto para manejo de rechazo crónico mediado por anticuerpos ${ }^{22}$ y se ha utilizado con éxito en pacientes trasplantados con COVID-19. ${ }^{23,24}$

\section{Tratamientos propuestos para manejo de COVID-19}

\section{Cloroquina (CLQ)/hidroxicloroquina (HCQ) con o sin azitromicina}

La cloroquina y la hidroxicloroquina se han utilizado por muchos años de manera efectiva para tratamiento del paludismo (malaria) y como adyuvante en enfermedades reumáticas como lupus y artritis reumatoide. Su uso en COVID-19 se debe a que en estudios experimentales se observó que inhibe la acidificación del endosoma requerido para la fusión del virus con la célula huésped, inhibe la fusión del autofagosomalisosoma e inactiva enzimas que el virus requiere para su replicación. Por otro lado, la azitromicina es un antibiótico macrólido utilizado en combinación con antimaláricos para el tratamiento de COVID-19. ${ }^{25}$

Los estudios clínicos son controversiales. Un estudio abierto, no aleatorizado, con 42 pacientes, aunque después de excluir 6 , se analizaron sólo 36 (20 tratados con HCQ y 16 controles), mostró reducción de la carga viral en pacientes que recibieron hidroxicloroquina (600 mg/día durante 10 días), dicha reducción fue mayor en cinco de seis casos que además recibieron azitromicina, sin embargo, no se analizó el impacto clínico y el seguimiento fue muy corto. ${ }^{26}$

Otro estudio de 181 pacientes con COVID-19 y neumonía (84 recibieron HCQ dentro de las 48 horas de su ingreso, ocho adicionales la recibieron después de 48 horas y 89 controles), no demostró diferencia en ingresos a terapia intensiva o muerte dentro de los siete días de seguimiento. ${ }^{27}$

En un estudio brasileño, doble ciego, aleatorizado, de grupos paralelos, comparó dos dosis de CLQ en adición a ceftriaxona o azitromicina, pero el reclutamiento se detuvo prematuramente debido a que en el grupo de dosis altas de CLQ $(650 \mathrm{mg}$ c/12 horas por 10 días) el $18.9 \%$ de los casos desarrolló prolongación del QT y el 2.7\% presentó taquicardia ventricular, con tendencia a mayor mortalidad que el grupo de dosis bajas ( $450 \mathrm{mg} \mathrm{c} / 12$ horas por 10 días). ${ }^{28}$

Múltiples estudios se están llevando a cabo en diferentes países en diferentes escenarios y estadios de la enfermedad. Sin embargo, debemos ser cautos con su uso ya que los antimaláricos en sobredosis (sobre todo en el contexto de enfermedad renal) pueden ocasionar alteración en las enzimas hepáticas, anemia hemolítica, hipotensión, hipocalemia, prolongación del QRS y QT, bloqueo AV, arritmias y coma, que pueden ser potencializados por la azitromicina; en niños tienen una brecha terapéutica estrecha y la ingesta accidental de una sola dosis de adulto puede tener toxicidad importante. ${ }^{25}$

\section{Remdesivir}

El remdesivir es un antiviral de amplio espectro, desarrollado en 2017 por Gilead Sciences para el tratamiento de la infección por el virus Ébola. Es una prodroga, análogo de adenosina, que afecta la correcta replicación del ARN viral y a su vez inhibe la ARN polimerasa-ARN dependiente del virus, cuya función sería identificar y corregir estos errores en la replicación de la cadena de ARN, errores que al no corregirse, causan una disminución en la producción de ARN viral. El remdesivir demostró eficacia in vitro para inhibir el crecimiento del virus del Ébola y otros coronavirus como SARS-CoV y el MERS-CoV; posteriormente, en estudios en ratones fue útil para tratar la infección por MERS-CoV y en modelos de monos Rhesus con enfermedad por virus del Ébola y SARS-CoV-2, así como para prevenir la infección por MERS-CoV en monos Rhesus. Sin embargo, no pudo demostrar utilidad en un ensayo clínico controlado para enfermedad de Ébola. ${ }^{29}$ Por otro lado, el Wuhan Virus Research Institute realizó experimentos in vitro de remdesivir en COVID-19 con células humanas de epitelio respiratorio y encontró que el remdesivir fue el agente antiviral con acción más potente y rápida, con un efecto inhibitorio del virus dosis dependiente, ubicándolo como el mejor candidato para su uso clínico. ${ }^{30,31}$

Por lo anterior y ante la ausencia de un tratamiento específico, el remdesivir se comenzó a utilizar de ma- 
Tabla 1: Concentrado de los estudios del uso de tocilizumab para tratamiento de COVID-19.

\begin{tabular}{|c|c|c|c|c|c|}
\hline Autor & Estudio/lugar & Población & COVID gravedad & Intervención & Resultados \\
\hline $\begin{array}{l}\text { CORIMUNO-TOCI trial } \\
\text { Press release. } \\
\text { NCT04331808 }\end{array}$ & $\begin{array}{l}\text { Ensayo clínico, con- } \\
\text { trolado, aleatorizado; } \\
\text { Francia }\end{array}$ & $\begin{array}{l}n=65 \text { (tocilizumab) vs } \\
64 \text { control; } 7 \text { centros }\end{array}$ & Moderado-severo & $\begin{array}{l}\text { Tocilizumab } 8 \mathrm{mg} / \mathrm{kg} \\
\text { día 1, segunda dosis } \\
\text { variable }\end{array}$ & $\begin{array}{l}\text { Datos preliminares } \\
\text { muestran menor morta- } \\
\text { lidad con tocilizumab }\end{array}$ \\
\hline Sciascia et al..$^{57}$ & Prospectivo, Italia & $\begin{array}{l}n=63, \text { edad promedio } \\
62.6 \text { años }\end{array}$ & Severo & $\begin{array}{l}\text { Tocilizumab } 8 \text { mg/kg } \\
\text { IV o } 324 \text { mg SC día } \\
\text { 1, segunda dosis sólo } \\
\text { en } 52\end{array}$ & $\begin{array}{l}\text { Mortalidad } 11 \% \text {, resolu- } \\
\text { ción fiebre, disminución } \\
\mathrm{PCR} \text {, ferritina, dímero D, } \\
\mathrm{PaO}_{2} / \mathrm{FiO}_{2} \text {; sin efectos } \\
\text { adversos }\end{array}$ \\
\hline Xu et al. ${ }^{58}$ & Retrospectivo, China & $\begin{array}{l}n=21, \text { edad promedio } \\
57 \text { años }\end{array}$ & $\begin{array}{l}\text { 19\% severo, IL6 prome- } \\
\text { dio: } 132 \mathrm{pg} / \mathrm{mL}\end{array}$ & $\begin{array}{l}\text { Tocilizumab } 400 \text { mg, } \\
\text { dosis única }\end{array}$ & $\begin{array}{l}\text { Mortalidad 0\%, hospita- } \\
\text { lizados } 10 \% \text {, alta } 90 \%\end{array}$ \\
\hline Luo et al..$^{59}$ & Retrospectivo, China & $\begin{array}{l}n=15, \text { edad promedio } \\
73 \text { años }\end{array}$ & $\begin{array}{l}\text { 47\% severo, IL6 prome- } \\
\text { dio: } 111 \mathrm{pg} / \mathrm{mL}\end{array}$ & $\begin{array}{l}\text { Tocilizumab 80-600 mg; } \\
\text { dosis promedio } 1.47 \\
\mathrm{mg} / \mathrm{kg}\end{array}$ & $\begin{array}{l}\text { Mortalidad 20\%, hospi- } \\
\text { talizados } 80 \%\end{array}$ \\
\hline
\end{tabular}

nera compasiva para el tratamiento de COVOD-19. ${ }^{32}$ Algunas series de casos mostraron aparente beneficio con su uso. ${ }^{32,33}$ Sin embargo, un estudio multicéntrico, aleatorizado, doble ciego, controlado con placebo realizado en China con 239 pacientes (con una relación 2:1, 158 con remdesivir y 79 con placebo) con COVID-19 en estado grave, mostró reducción en los días para alcanzar mejoría pero sin alcanzar diferencia estadística, al igual que no hubo diferencia en mortalidad. ${ }^{34}$ Recientemente, se dio a conocer los resultados de un ensayo clínico, multicéntrico, que incluyó 1,063 pacientes con COVID-19 considerado grave, que mostró un menor tiempo para la recuperación comparado con el grupo placebo (11 vs 15 días), con una ligera reducción en mortalidad (8 vs 11.6\%), aunque esta no alcanzó significancia estadística ( $p=0.059$ ). Los efectos secundarios más frecuentes son rash, diarrea, hipotensión e incremento de enzimas hepáticas. Queda claro la desesperación por tener una herramienta terapéutica, ya que con estos resultados tan limitados, la FDA emitió una autorización de emergencia el 01 de mayo de 2020, para su uso en pacientes con COVID-19 grave.

\section{Favipiravir}

Favipiravir es un análogo nucleósido, inhibidor potente y selectivo de la ARN polimerasa viral. ${ }^{35} \mathrm{Si}$ bien favipiravir fue aprobado para el tratamiento de influenza en Japón desde 2014, también inhibe la replicación de otros virus ARN por lo que fue utilizado para el tratamiento del Ébola. ${ }^{36}$ En marzo de 2020 fue aprobado como el primer antiviral anti-COVID-19 en China, siendo la dosis recomendada en China de 1200 mg BID el día 1 y 400 mg BID los días 2-5 vía oral. El efecto secundario serio del favipiravir es la teratogenicidad, por otro lado se han reportado anormalidades en enzimas hepáticas, síntomas psiquiátricos, gastrointestinales y elevación de ácido úrico. ${ }^{37}$

Actualmente existen varios estudios controlados en curso, principalmente combinado con otros agentes; algunos resultados iniciales demuestran que podría ser un antiviral prometedor. Cai et al. ${ }^{37}$ compararon favipiravir (1,600 mg BID/día 1 y 600 mg BID días 2-14) vs lopinavir/ritonavir (400/100 mg bid) en adición a interferóna1b (60 mg BID/día), encontrando que favipiravir se asoció a un menor tiempo de aclaramiento del virus (4 vs 11 días, $p<0.001)$ y una mejoría significativa de la imagen de tórax (91.43 vs $62.22 \%, p=0.004$ ). Por otro lado, Chen et al..$^{38}$ compararon favipiravir $(1,600 \mathrm{mg}$ BID día 1 y 600 mg BID días 2-14) vs arbidol (200 mg TID/ día) no encontrando diferencias en la tasa de recuperación clínica al día 7 con 71/116 pacientes vs 62/120 pacientes, $p=0.1396$; pero Favipiravir se asoció a menor tiempo para aliviar fiebre y tos. En ambos estudios se excluyeron a pacientes con COVID-19 severo.

Un área todavía incierta es el uso de este antiviral en pacientes críticamente enfermos, Irie et al. ${ }^{39}$ repor- 
taron datos farmacocinéticos en siete pacientes críticamente enfermos que recibieron el medicamento $(1,600$ mg BID día 1, 600 mg BID días 2-5) encontrando que la mayoría de las mediciones tenían concentraciones con niveles por debajo del límite de la cuantificación lo que genera preocupación y ahonda en la necesidad de estudios en este grupo de pacientes.

\section{Lopinavir/ ritonavir (Kaletra)}

Lopinavir es un inhibidor de proteasa para $\mathrm{VIH}$, tiene pobre biodisponibilidad y vida media corta. Por otro lado, ritonavir es un inhibidor de citocromo CYP3A4, el cual inhibe el metabolismo de lopinavir. La combinación lopinavir/ ritonavir incrementa significativamente la biodisponibilidad del lopinavir e incrementa su efecto antiviral in vivo. ${ }^{40}$

Previamente, Kaletra fue aprobada por la FDA para el tratamiento del VIH desde el año 2000 y fue utilizado en el brote de SARS-CoV en 2003. ${ }^{41}$ Chan et al. ${ }^{42}$ demostraron una disminución en la mortalidad en el grupo que recibió lopinavir/ritonavir en comparación a un grupo control 2.3 vs $15.6 \%$, así mismo demostraron que la eficacia del medicamento se logra mejor cuando se administra en la fase temprana de la infección por coronavirus. Por los antecedentes con brotes de coronavirus previos, lopinavir/ritonavir se utilizó en la infección por SARS-CoV-2 en China a dosis de 400 $\mathrm{mg} / 100 \mathrm{mg}$ BID por 10 días. ${ }^{43}$

Cao et al. ${ }^{44}$ desarrollaron un estudio aleatorizado con 199 pacientes con COVID-19 severo en Wuhan/ China, se evidenció que el grupo de lopinavir/ritonavir falló para demostrar beneficio clínico en el tiempo de recuperación y en la mortalidad. Interesantemente hay reportes que indican que la farmacodinamia de lopinavir/ritonavir no permitiría alcanzar concentraciones séricas capaces de inhibir el SARS-CoV-2. ${ }^{45}$ Por otra parte, Hung et al. ${ }^{46}$ realizaron un estudio multicentríCo, con 127 pacientes con COVID-19 leve a moderado y mostraron que el tratamiento de triple combinación de Interferón beta $1 \mathrm{~b}$, lopinavir/ritonavir y ribavirina es superior al tratamiento con lopinavir/ritonavir solo, en aliviar síntomas y disminuir la duración de la carga viral y estancia hospitalaria. Por todo lo anterior todavía faltan estudios que demuestren efectividad de este medicamento para el tratamiento de COVID-19.

\section{Ribavirina}

Ribavirina es un análogo nucleósido (de guanosina), aprobado por la FDA para tratar varias infecciones virales como el virus de hepatitis $\mathrm{C}$, virus sincitial res- piratorio y algunas fiebres hemorrágicas virales. Si bien existe evidencia controversial de su efecto contra MERS ${ }^{47}$ en China se inició su uso como tratamiento para COVID-19, combinado con interferón o lopinavir/ ritonavir a dosis de $500 \mathrm{mg}$ IV 2-3 veces/día por 10 días. ${ }^{48}$ El riesgo de toxicidad in vivo (principalmente anemia hemolítica y leucopenia) originó que algunos equipos médicos detuvieran su uso. Contrario a esto, y como ya se comentó, Hung et al. ${ }^{46}$ realizaron un estudio en 127 pacientes con COVID-19 leve a moderado, comparando: lopinavir/ritonavir 400/100 mg BID + ribavirina $400 \mathrm{mg} \mathrm{BID} \mathrm{+} \mathrm{interferon} \mathrm{beta1b} 8$ millones UI cada 48 horas vs lopinavir/ritonavir. El grupo con tratamiento combinado fue superior en aliviar síntomas y acortar la duración de viremia y estancia hospitalaria. Sólo se reportaron náuseas y diarrea como efectos secundarios en ambos grupos; lo cual demuestra que todavía faltan estudios controlados que demuestren la utilidad de este medicamento.

\section{Umifenovir (Arbidol)}

Arbidol es una droga antiviral no nucleósido que inhibe la fusión de la membrana viral con el endosoma. Puede inhibir una variedad de virus como virus influenza, virus sincitial respiratorio, adenovirus, virus de hepatitis C y SARS-CoV. ${ }^{49}$ Se ha utilizado sólo o en combinación para tratamiento de COVID-19 con resultados no satisfactorios. ${ }^{38,50}$

\section{Interferón}

Interferones $\alpha / \beta$ tipo I, son una familia de citocinas con propiedades antivirales de amplio espectro; inhiben la replicación de virus ADN y ARN a diferentes estadios de su ciclo replicativo y activan poblaciones del sistema inmune para limpiar la infección viral. ${ }^{51}$ Fueron utilizados en otras infecciones por coronavirus con enfermedad severa y no demostraron beneficio y la presencia de efectos secundarios tóxicos hacen revalorar su uso en pacientes graves. ${ }^{47}$ Zhou et al. ${ }^{52}$ estudiaron a 77 pacientes con COVID-19 moderado a los cuales se les trato con interferón alfa-2b vs interferón alfa- $2 b+$ umifenovir vs umifenovir. Encontraron que los grupos tratados con interferón que la carga viral se negativizó mas rápido y la inflamación sistémica se redujo más rápido que el grupo con umifenovir solo. Sin embargo estos grupo fueron más jóvenes y con menos comorbilidades por lo que sus resultados deben ser tomados con precaución. Adicionalmente, en trasplantes incrementa el riesgo de rechazo. 


\section{Inhibidores IL-6 e IL-1}

La infección por SARS-CoV-2 en sus formas severas, desarrolla síndrome de liberación de citocinas (tormenta de citocinas) que se caracteriza por niveles elevados de citocinas inflamatorias, entre estas importantemente IL-6 e IL-1, así como IL-10 y TFN- $\alpha .^{53}$ $\mathrm{Al}$ igual que para los inhibidores de IL-1, la evidencia no es contundente para estar a favor o en contra del uso de inhibidores de IL-6, ${ }^{54}$ los cuales actúan unién- dose al receptor de IL-6 como tocilizumab y sarilumab, o uniendose directamente a la IL-6 como siltuximab. ${ }^{55}$

Tocilizumab. Es un anticuerpo monoclonal humanizado (subtipo IgG1) contra el receptor de IL-6, utilizado para el tratamiento de artritis reumatoide y otras enfermedades autoinmunes, así como utilizado para tratar síndrome de liberación de citocinas causado por inmunoterapia. Actualmente emergió como alternativa terapéutica para la tormenta de citocinas en pacientes con COVID-19. ${ }^{56}$

Tabla 2: Resumen de los estudios del uso de plasma de convalecientes para tratamiento de COVID-19.

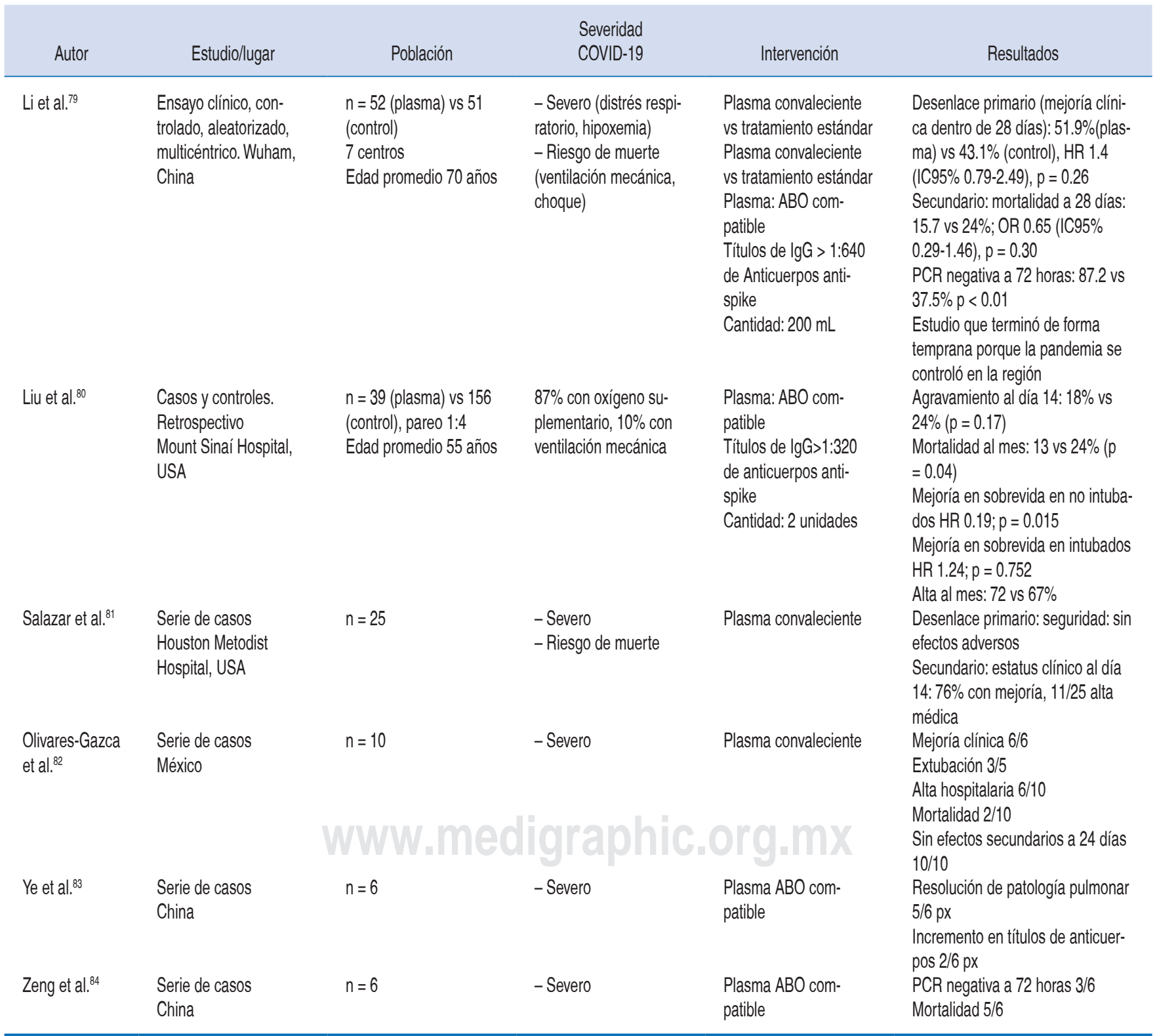


La dosis recomendada de tocilizumab es $8 \mathrm{mg} / \mathrm{kg}$ dosis única, sin exceder $800 \mathrm{mg}$, esta dosis se puede repetir 12 horas posterior si no hay mejoría clínica. Los efectos secundarios son: reacciones asociadas a la infusión, perforación gastrointestinal, hepatotoxicidad, reacción por hipersensibilidad. Su uso puede incrementar el metabolismo de drogas que son sustratos CYP 450 y este efecto persistir por semanas después de la terapia. ${ }^{54}$

Como se describe en la Tabla 1, no existen estudios aleatorizados concluidos que demuestren el efecto positivo del tocilizumab, los resultados preliminares (aun no publicados) de un estudio aleatorizado en Francia (ClinicalTrials.gov NCT04331808) muestran que la mortalidad en el grupo de tocilizumab fue menor que el grupo control. El resto de estudios sugieren que tocilizumab podría ser un tratamiento efectivo en pacientes con COVID-19 severo, puesto que se evidencia una mejoría clínica posterior a su administración aunque queda duda si los pacientes habrían mejorado por el soporte incluso sin recibir el medicamento. ${ }^{57-60}$

Sarilumab. Es otro anticuerpo monoclonal IgG1 que bloquea el receptor de IL-6. Está aprobado para el tratamiento de la artritis reumatoide mas no para el síndrome de liberación de citocinas. Un reporte inicial de ocho casos, reportó mejoría y egreso más temprano en siete de ocho pacientes con COVID-19.61 Un estudio abierto comparó 28 pacientes tratados con sarilumab 400 mg contra 28 pacientes con el estándar de cuidado, sin encontrar diferencias en recuperación (61 vs $64 \%, p=n s$ ) y mortalidad (7 vs $18 \%, p=n s) .{ }^{62}$

Actualmente se lleva a cabo un estudio Fase2 (ClinicalTrials.gov NCT04315298) donde se aleatorizó a recibir $400 \mathrm{mg}, 200 \mathrm{mg}$ o placebo. El reporte preliminar muestra una mortalidad de $28 \%$ vs $46 \%$ vs $55 \%$, pero debemos esperar los resultados finales. Los efectos secundarios del medicamento reportados son neutropenia, trombocitopenia, reacción a la transfusión y procesos infecciosos. Debe recordarse que al realizar el bloqueo de receptores IL-6 también se bloquea la respuesta ante un proceso infeccioso y se pueden evidenciar reactivaciones de infecciones crónicas como tuberculosis por ejemplo.

Siltuximab. Es un anticuerpo monoclonal quimérico que se une directamente a IL-6 y evita su unión a su receptor ya sea soluble o de membrana, evitando la activación de la vía de las quinasas Janus. Está indicado para el tratamiento de la enfermedad de Castleman. Es el de vida media más larga, de $16.3 \pm$ 4.2 días, por lo que una sola dosis podría ser suficien- te en COVID-19. Los eventos adversos más comunes son hipertensión (13\%), fatiga (8\%), náusea $(7 \%)$, neutropenia $(7 \%)$ y vómito $(5 \%)$. También disminuye la actividad del citocromo P450. ${ }^{55,63}$

Anakinra. Es un antagonista recombinante del receptor de interleucina-1 humano, aprobado para el tratamiento de la artritis reumatoide y la enfermedad inflamatoria multisistémica de inicio neonatal. En un estudio retrospectivo de 29 pacientes con COVID-19, aquellos con anakinra en combinación con el tratamiento estándar tuvieron una mejoría respiratoria más rápida en comparación con 16 pacientes que recibieron sólo terapia estándar (72 y 50\%, respectivamente). ${ }^{64}$

\section{Esteroides}

Actualmente, las guías de tratamiento recomiendan el uso de dexametasona en pacientes con COVID-19 que se encuentran bajo ventilación mecánica o con oxígeno suplementario a dosis de $6 \mathrm{mg} / \mathrm{kg}$ hasta por 10 días. ${ }^{54}$

Si bien los esteroides han sido ampliamente utilizado a enfermedades como SARS, MERS e influenza severa, la evidencia que respalda su uso es débil y contradictoria. En SARS y MERS puede retrasar el aclaramiento viral, además de las complicaciones asociadas a su uso, sin diferencia en mortalidad, ${ }^{65,66} \mathrm{y}$ en neumonía por influenza se asoció con mayor mortalidad. ${ }^{67}$

Desde el inicio de la pandemia, el uso de esteroides fue hasta en el $45 \%$ de los pacientes. ${ }^{68}$ Pequeñas cohortes retrospectivas demostraron una reducción rápida de la hipoxia, reducción de los requerimientos de la ventilación mecánica y reducción en la transferencia a una unidad de terapia intensiva. ${ }^{69}$ Otros estudios en cambio, reportaron un incremento en el riesgo de disfunción multiorgánica y por ende sin beneficio en mortalidad. ${ }^{70}$

El estudio RECOVERY, ${ }^{71}$ multicéntrico, aleatorizado, donde 2,104 pacientes recibieron dexametasona y 4,321 recibieron cuidado estándar, la mortalidad global a 28 días fue del $21.6 \%$ (dexametasona) vs $24.6 \%$ (control), $\mathrm{p} \leq 0.01$; la mortalidad fue menor en los pacientes que requerían ventilación mecánica (29 vs $40.7 \%$ ) y en los pacientes con oxígeno suplementario ( 21.5 vs $25 \%$ ) y no encontró beneficio en los pacientes que no requerían oxígeno suplementario. Es de resaltar que remdesivir no fue parte del tratamiento por lo que no se sabe el efecto de administrar ambas terapias. 
Tabla 3: Guías de los Institutos Nacionales de Salud (NIH) para el tratamiento de COVID-19*.54

Medicamentos

Antivirales

Remdesivir

Cloroquina o hidroxicloroquina

Otros antivirales

Inmunomoduladores

Productos derivados de la sangre

Dexametasona

Otros inmunomoduladores
- COVID-19 severo: en lugares donde remdesivir está limitado, debe ser priorizado para pacientes que requieren oxígeno suplementario pero que no están bajo ventilación mecánica. Tiempo: cinco días (BI)

- COVID-19 leve a moderado: evidencia insuficiente para dar recomendación a favor o en contra de su uso

- No se recomienda su uso, excepto en ensayos clínicos (Alll)

- No se recomienda el uso de altas dosis de cloroquina (Al)

No se recomienda el uso de los siguientes antivirales, excepto en ensayos clínicos:

- Hidroxicloroquina/azitromicina (Alll) por riesgo potencial de toxicidad

- Lopinavir/ritonavir u otros inhibidores de proteasa de uso para VIH (AIII), por farmacodinamia desfavorable y porque los estudios no han mostrado beneficio clínico

- Evidencia insuficiente para recomendar a favor o en contra del uso de:

- Plasma convaleciente

- Inmunoglobulinas SARS-CoV-2

- No se recomienda el uso de lo siguiente, excepto en ensayos clínicos:

- Células madre mesenquimatosas (Alll)

- Inmunoglobulina (IVIG) no específica para SARS-CoV-2 (AIII)

- Se recomienda el uso de dexametasona (6mg/día hasta por 10 días) en pacientes con ventilación mecánica (Al) y en pacientes con oxígeno suplementario (BI)

- No se recomienda el uso de dexametasona en pacientes sin oxígeno suplementario (Al)

- Evidencia insuficiente para recomendar a favor o en contra del uso de:

- Inhibidor IL-1

- Inhibidor IL-6

- Interferon-beta

- No se recomienda el uso de lo siguiente, excepto en ensayos clínicos:

- Interferones (alfa o beta) para COVID-19 severo o críticamente enfermos (Alll)

- Inhibidores de Bruton tirosincinasa, Inhibidores Janus cinasa (AllI)

Recomendaciones: $\mathrm{A}$ = fuerte, $\mathrm{B}=$ Moderada, $\mathrm{C}=$ Opcional.

I: Uno o más estudios controlados aleatorizados, II: Uno o más estudios bien diseñados, no aleatorizados o cohortes observacionales, III: Opinión de expertos *Actualización 17 julio 2020.

\section{Inmunoglobulinas SARS-CoV-2 no específicas}

IVIG se utiliza para tratar una variedad de enfermedades inflamatorias, autoinmunes, infecciosas y virales. Modula la respuesta inmune vía múltiples mecanismos incluyendo el bloqueo de varias citocinas proinflamatorias. ${ }^{72}$ Los efectos secundarios son cefalea, mialgias, artralgias, fiebre, fatiga, rash, nausea, vómitos, eritema, hipo/hipertensión, taquicardia y sobrecarga de volumen.

Sakoulas $\mathrm{G}$ et al, ${ }^{73}$ desarrollaron un pequeño estudio aleatorizado en pacientes con COVID-19 grave; 16 pacientes recibieron IVIG $(0.5 \mathrm{~g} / \mathrm{kg} /$ día *3 con metilprednisolona $40 \mathrm{mg}$ ) vs 17 con cuidado estándar. Encontraron que IVIG mejoró la hipoxia y redujo la estancia hospitalaria (11 vs 19 días) y progresión a ventilación mecánica (2/14 vs 7/12).
Por otro lado, Shao et al, ${ }^{74}$ reportaron que la aplicación de IVIG $(n=174)$ no repercute en la mortalidad a 28 y 60 días en pacientes con COVID-19 vs sólo manejo estándar $(n=151)$, pero al realizar un subanálisis de los pacientes con COVID-19 severo encontraron que podría existir un beneficio en mortalidad a 28 días, y disminución de la respuesta inflamatoria, así mismo que la aplicación temprana (< 7 días) tendría mayor efecto que la aplicación tardía.

\section{Plasma convaleciente}

El plasma convaleciente ha sido utilizado en el tratamiento de neumonías virales desde inicios del siglo $X X$. Por ejemplo, existen reportes de su uso durante la influenza española, ${ }^{75}$ así como para SARS-CoV en 
2003 con evidencia de beneficio si se aplicaba dentro de los 14 días del inicio de los síntomas. ${ }^{76}$

El plasma convaleciente se refiere a plasma obtenido de pacientes recientemente recuperados de la infección viral, el cual se espera que contenga niveles elevados de anticuerpos policlonales contra el virus. El mecanismo de acción principal es reducción de la viremia (inmunidad pasiva) ${ }^{77}$ y modificación de la respuesta inflamatoria (inmunidad activa). Habrá mayor nivel de anticuerpos neutralizantes a menor tiempo desde el inicio de los síntomas, menor edad y mayor severidad de la enfermedad. ${ }^{78}$ Los estándares y métodos para la medición de los anticuerpos neutralizantes no han sido establecidos. La variabilidad en el nivel de anticuerpos del plasma convaleciente puede tener un impacto en la eficacia del tratamiento.

Actualmente, las guías de tratamiento para COVID-19 indican que la evidencia existente no es contundente para tomar una postura a favor o en contra del uso de plasma convaleciente. ${ }^{54} \mathrm{Li}$ et al, ${ }^{79}$ en un ensayo clínico aleatorizado, multicéntrico, la aplicación de plasma convaleciente a un grupo de pacientes con SARS-CoV-2 severo, logró un mayor porcentaje de pacientes con mejoría clínica, disminuyó la mortalidad y mejoró el porcentaje de negativización de PCR a las 72 horas, pero sin lograr significancia estadística. El estudio terminó anticipadamente porque la situación de la pandemia mejoró en la región, esto condicionó que no reclutaran la población deseada. Resultados similares fueron reportados por Liu et al, ${ }^{80}$ en el Hospital Mount Sinai de Nueva York. En la Tabla 2 se muestran otras series de casos que demuestran que el efecto benéfico del plasma convaleciente no es contundente como para su recomendación. ${ }^{81-84}$

Los riesgos de la aplicación del plasma convaleciente son muy poco comunes; el análisis de seguridad de los primeros 5,000 pacientes del Programa Nacional de Acceso Expandido a plasma convaleciente de Estados Unidos reporta eventos adversos serios en $<1 \%$, dentro de los cuales se reportaron sobrecarga asociada a la transfusión, lesión pulmonar aguda asociada a la transfusión y reacciones alérgicas severas. ${ }^{85}$

\section{Uso de inhibidores de la enzima convertidora de angiotensina o bloqueadores del receptor AT1}

Al inicio de la epidemia los estudios descriptivos, sin uso de controles, mostraron un mayor uso de medicamentos que afectan el eje renina-angiotensina-aldosterona en el grupo de pacientes que requerían hospitalización por COVID-19 o en los que tenían cuadros más graves. Se adjudicó a que el virus usa la ACE2 como receptor para su ingreso a las células humanas. Sin embargo, recientemente se publicaron 3 estudios observacionales, en uno realizado en Italia, Giuseppe Mancia y colaboradores ${ }^{86}$ incluyeron 6,732 casos de COVID-19 y 30,759 controles sin COVID-19 de las mismas comunidades; en el segundo de Nueva York, Harmony R. Reynolds y colaboradores ${ }^{87}$ evaluaron 12,594 casos de COVID-19; y en el tercero, multicéntrico, con hospitales de 3 continentes, Mandeep R Me$\mathrm{hta}^{88}$ y colaboradores analizaron 8,910 pacientes con COVID-19; en los tres estudios se tuvo el mismo resultado, el uso de inhibidores de la enzima convertidora de angiotensina o los bloqueadores del receptor AT1 no tienen asociación con el desarrollar COVID-19 o con su evolución. Es la enfermedad cardiovascular la que en todo caso se asocia con mal pronóstico. Estos mismos resultados se corroboran en tres metaanálisis recientes. ${ }^{89-91}$

\section{ACE2 como blanco terapéutico}

Como se menciona en un capítulo previo, el SARSCoV y el SARS-CoV-2 invaden la célula del huésped por la unión de la proteína glucosilada S (S de spike) del virus con la enzima convertidora de angiotensina humana tipo 2 (ACE2), paso crucial en el desarrollo de la infección viral. Esta unión causa regulación a la baja de la expresión de ACE2, así, su deficiencia y regulación alterada, son mecanismos patogénicos propuestos de la progresión del daño pulmonar. ${ }^{92} \mathrm{El}$ interferir en esta unión de la ACE2 con la proteína $S$ viral es atractiva desde el punto de vista terapéutico y para ello se ha desarrollado el APN01 (ACE2 humano recombinante; NCT00886353), que se encuentra en evaluación en estudios fase III por Apeiron Biologics, para el tratamiento de COVID-19.93

Otro enfoque es utilizar ligandos de ACE2 para que induzcan cambios conformacionales y así reducir la capacidad de unión del virus a este receptor de membrana. Así nació la molécula pequeña XNT, un activador de ACE2 que se encuentra en estudios preclínicos en la esfera cardiovascular. Esta molécula fue capaz de inhibir la interacción proteína-proteína entre ACE2 y un anticuerpo IgG dirigido contra ACE2 presente en enfermedades autoinmunes, lo que demuestra que cambios conformacionales inducidos por estas moléculas pequeñas (XNT) pueden bloquear la unión de ACE2 con otras proteínas ligando. ${ }^{93}$ Así como el XNT, existen múltiples fármacos aprobados por la FDA para otros fines y que tienen 
el mismo efecto sobre ACE2, como el labetalol (alfa y betabloqueador mixto), aprindina (antiarrítmico clase $1 b)$, fominoben (antitusígeno no opiáceo), hicantona (tratamiento de esquistosomiasis), clorprotixeno (antipsicótico), hidroxizina (antihistamínico), entre otros, que podrían tener un uso potencial en el manejo de COVID-19 desde el punto de vista teórico..$^{93,94}$

\section{Otras terapias}

Múltiples fármacos adyuvantes se han utilizado o se están probando para el manejo de pacientes hospitalizados con COVID-19. Dentro de ellos están:95,96

- El mesilato de Camostat, un inhibidor de la enzima transmembrana proteasa de serina 2 (TMPRSS2), que reduce la infección de células pulmonares in vitro por SARS-CoV-2.

- La ulinastatina, un inhibidor de la proteasa de serina con efectos antiinflamatorios aproba- dos en China y Japón para el tratamiento de la pancreatitis aguda y la sepsis, en estudio para uso en COVID-19.

- Los inhibidores de JAK-STAT, como baricitinib, fedratinib y ruxolitinib, son antiinflamatorios potentes que están aprobados para la artritis reumatoide y la mielofibrosis. Los pacientes infectados con SARS-CoV-2 con niveles elevados de citocinas pueden beneficiarse del uso de estos medicamentos.

- Terapia con células madre.

- Terapia anti-TNF $\alpha$, como adalimumab o infliximab, utilizados en el tratamiento de varias enfermedades autoinmunes como la AR, enfermedad inflamatoria intestinal y espondilitis anquilosante. Con potencial utilidad en la inflamación asociada a COVID-19.

- Estatinas, por su potencial efecto inmunomodulador.

Tabla 4: Interacciones farmacológicas de los inmunosupresores utilizados en trasplantes y medicamentos utilizados para el tratamiento de COVID-19.

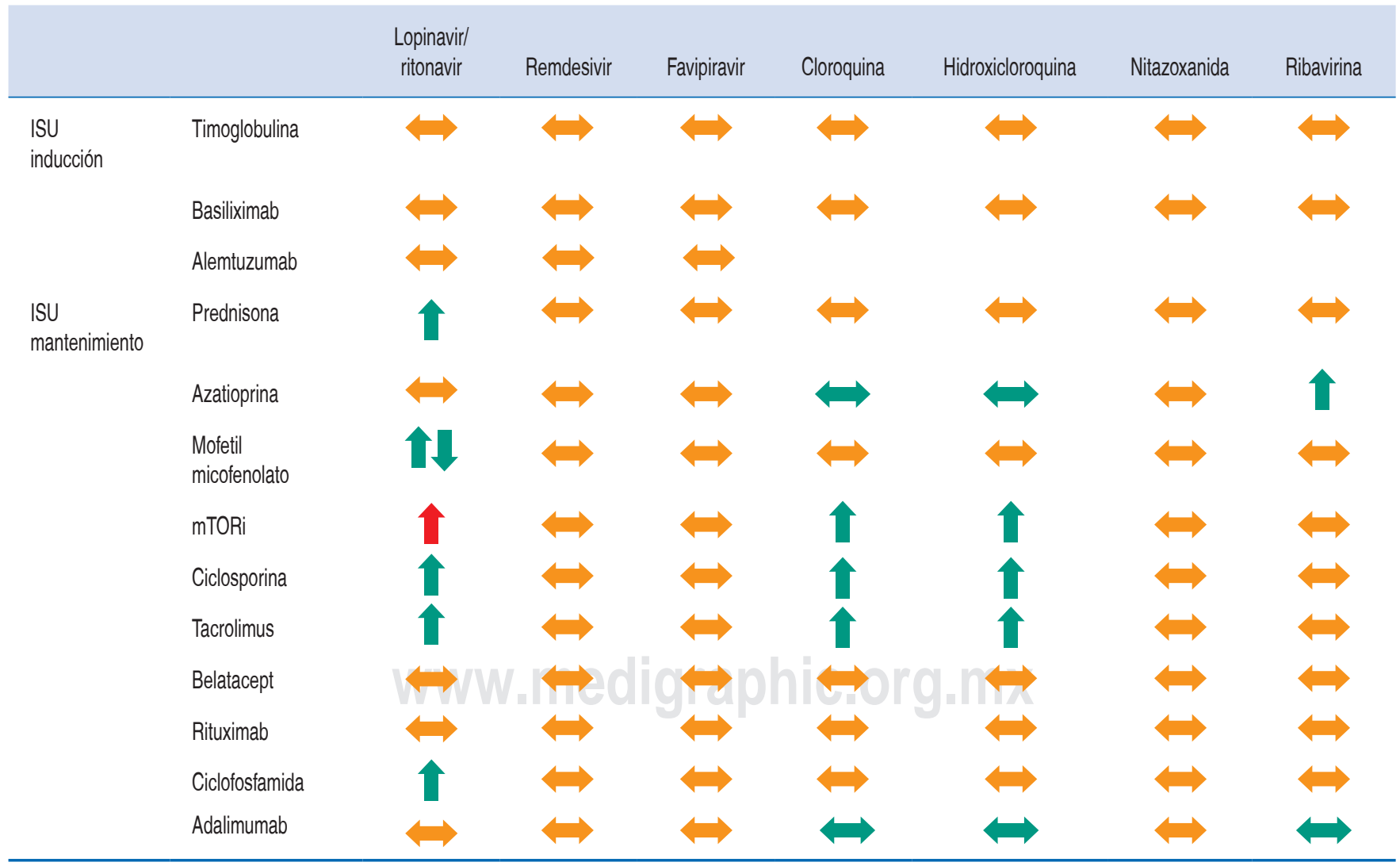

$\leftrightarrow$ Sin efecto significativo, $\uparrow$ : potencial exposición aumentada, $\downarrow$ : potencial exposición disminuida

— Sin interacción clínica significativa, — Potenciales interacciones que pueden requerir ajuste de dosis o monitorización de la misma, — No deben administrarse de forma conjunta 
- Colchicina, por su conocido efecto antiinflamatorio.

Con todo lo anterior, queda claro que las estrategias terapéuticas para COVID-19 van evolucionando continuamente, en la Tabla 3 se muestra un resumen de las recomendaciones actuales de los Institutos $\mathrm{Na}$ cionales de Salud (NIH) para el tratamiento de la infección por SARS-CoV-2, mismas que se actualizan periódicamente en base a la nueva evidencia de los ensayos clínicos. ${ }^{54}$

\section{Interacciones farmacológicas con los inmunosupresores}

Por otra parte y en vista de la continua evolución de recomendaciones sobre medicamentos dirigidos contra el SARS-CoV-2 y la polifarmacia habitual de pacientes trasplantados es importante, antes de iniciar cualquier terapia, revisar las posibles interacciones y efectos secundarios de los medicamentos a utilizar, algunas de las cuales se resumen en la Tabla $4 .{ }^{97}$

\section{CONCLUSIÓN}

El manejo de la inmunosupresión en pacientes trasplantados con COVID-19 no está definido. Con base a opinión de expertos y extrapolando lo que se haría ante infecciones sistémicas similares a COVID-19 se recomienda disminuir inmunosupresión de acuerdo a la gravedad del cuadro del paciente, iniciando con la suspensión de antiproliferativos y continuando con inhibidores de calcineurina, sin suspender esteroides. El uso de cualquier terapia para COVID-19 deberá ser con cautela, siempre basados en la evidencia disponible al menos para población general y tomando en cuenta las particularidades del paciente trasplantado y las interacciones farmacológicas.

\section{REFERENCIAS}

1. Cravedi P, Suraj SM, Azzi Y, Haverly M, Farouk S, Perez-Saez MJ et al. COVID-19 and kidney transplantation: results from the TANGO International Transplant Consortium. Am J Transplant. 2020.

2. Akalin E, Azzi Y, Bartash R, Seethamraju H, Parides M, Hemmige $V$ et al. Covid-19 and Kidney Transplantation. N Engl J Med. 2020; 382: 2475-2477.

3. Zaza G, Benedetti C, Fribourg M, Maggiore U, Azzi J, Riella LV et al. SARS-CoV-2 pandemic and the need for transplantoriented trials. Transpl Int. 2020; 33: 966-968.

4. Morales-Buenrostro LE. Terapia de inducción con anticuerpos monoclonales y policlonales: basiliximab, timoglobulina y alemtuzumab. In: Alberú JL. Trasplantomecum renal. $2^{a}$ ed. Barcelona, España: Publicaciones Permanyer; 2011. pp. 69-75.
5. Ekberg H, Bernasconi C, Tedesco-Silva H, Vitko S, Hugo $C$, Demirbas $A$ et al. Calcineurin inhibitor minimization in the Symphony study: observational results 3 years after transplantation. Am J Transplant. 2009; 9: 1876-1885.

6. Florman S, Becker T, Bresnahan B, Chevaile-Ramos A, Carvalho D, Grannas $G$ et al. Efficacy and safety outcomes of extended criteria donor kidneys by subtype: subgroup analysis of BENEFIT-EXT at 7 years after transplant. Am J Transplant. 2017; 17: 180-190.

7. Zaltzman JS. Is there a role for mTOR inhibitors in renal transplantation? Transplantation. 2017; 101: 228-229.

8. Hu Q, Zhong Z, Xiong Y, Ye S, Wang Y, Ye Q. Management of immunosuppression in kidney transplant recipients with COVID-19 pneumonia: a summary of 41 confirmed cases reported worldwide. Transpl Infect Dis. 2020: e13425.

9. Gandolfini I, Delsante M, Fiaccadori E, Zaza G, Manenti L, Degli Antoni A et al. COVID-19 in kidney transplant recipients. Am J Transplant. 2020; 20: 1941-1943.

10. Maggiore U, Abramowicz D, Crespo M, Mariat C, Mjoen G, Peruzzi $L$ et al. How should I manage immunosuppression in a kidney transplant patient with COVID-19? An ERA-EDTA DESCARTES expert opinion. Nephrol Dial Transplant. 2020; 35 : 899-904.

11. Vistoli F, Furian L, Maggiore U, Caldara R, Cantaluppi V, Ferraresso $\mathrm{M}$ et al. COVID-19 and kidney transplantation: an Italian Survey and Consensus. J Nephrol. 2020; 33: 667-680.

12. Mirjalili M, Shafiekhani M, Vazin A. Coronavirus disease 2019 (COVID-19) and transplantation: pharmacotherapeutic management of immunosuppression regimen. Ther Clin Risk Manag. 2020; 16: 617-629.

13. Pereira MR, Mohan S, Cohen DJ, Husain SA, Dube GK, Ratner LE et al. COVID-19 in solid organ transplant recipients: Initial report from the US epicenter. Am J Transplant. 2020; 20: 18001808.

14. Willicombe M, Thomas D, McAdoo S. COVID-19 and calcineurin inhibitors: should they get left out in the storm? J Am Soc Nephrol. 2020; 31: 1145-1146.

15. Marx D, Moulin B, Fafi-Kremer S, Benotmane I, Gautier G, Perrin $\mathrm{P}$ et al. First case of COVID-19 in a kidney transplant recipient treated with belatacept. Am J Transplant. 2020; 20: 1944-1946.

16. Ahmad SH, Smith R, Camilleri B. Belatacept, kidney transplantation and COVID-19: Successful management of the first reported case within the United Kingdom. Clin Transplant. 2020: e14026.

17. Nguyen LS, Vautier M, Allenbach $Y$, Zahr N, Benveniste O, Funck-Brentano $\mathrm{C}$ et al. Sirolimus and mTOR inhibitors: a review of side effects and specific management in solid organ transplantation. Drug Saf. 2019; 42: 813-825.

18. Johnson KM, Belfer JJ, Peterson GR, Boelkins MR, Dumkow LE. Managing COVID-19 in renal transplant recipients: a review of recent literature and case supporting corticosteroid-sparing immunosuppression. Pharmacotherapy. 2020; 40: 517-524.

19. Russell CD, Millar JE, Baillie JK. Clinical evidence does not support corticosteroid treatment for 2019-nCoV lung injury. Lancet. 2020; 395: 473-475.

20. Cao W, Liu X, Bai T, Fan H, Hong K, Song $\mathrm{H}$ et al. Highdose intravenous immunoglobulin as a therapeutic option for deteriorating patients with coronavirus disease 2019. Open Forum Infect Dis. 2020; 7: ofaa102.

21. Xie Y, Cao S, Dong H, Li Q, Chen E, Zhang W et al. Effect of regular intravenous immunoglobulin therapy on prognosis of severe pneumonia in patients with COVID-19. J Infect. 2020; 81 (2): 318-356. 
22. Choi J, Aubert O, Vo A, Loupy A, Haas M, Puliyanda D et al. Assessment of tocilizumab (anti-interleukin-6 receptor monoclonal) as a potential treatment for chronic antibody-mediated rejection and transplant glomerulopathy in hla-sensitized renal allograft recipients. Am J Transplant. 2017; 17: 2381-2389.

23. Fontana F, Alfano G, Mori G, Amurri A, Tei L, Ballestri M et al. COVID-19 pneumonia in a kidney transplant recipient successfully treated with tocilizumab and hydroxychloroquine. Am J Transplant. 2020; 20: 1902-1906.

24. Hammami MB, Garibaldi B, Shah P, Liu G, Jain T, Chen PH et al. Clinical course of COVID-19 in a liver transplant recipient on hemodialysis and response to tocilizumab therapy: a case report. Am J Transplant. 2020; 20 (8): 2254-2259.

25. Wong A. COVID-19 and toxicity from potential treatments: panacea or poison. Emerg Med Australas. 2020; 32 (4): 697699.

26. Gautret P, Lagier JC, Parola P, Hoang VT, Meddeb L, Mailhe $M$ et al. Hydroxychloroquine and azithromycin as a treatment of COVID-19: results of an open-label non-randomized clinical trial. Int J Antimicrob Agents. 2020; 56 (1): 105949.

27. Mahevas M, Tran VT, Roumier M, Chabrol A, Paule R, Guillaud C et al. Clinical efficacy of hydroxychloroquine in patients with covid-19 pneumonia who require oxygen: observational comparative study using routine care data. BMJ. 2020; 369: $\mathrm{m} 1844$.

28. Borba MGS, Val FFA, Sampaio VS, Alexandre MAA, Melo GC, Brito $M$ et al. Effect of high vs low doses of chloroquine diphosphate as adjunctive therapy for patients hospitalized with severe acute respiratory syndrome coronavirus 2 (SARSCoV-2) infection: a randomized clinical trial. JAMA Netw Open. 2020; 3: e208857.

29. Al-Tawfiq JAA-H, A.H. Memish, Z.A. Remdesivir as a possible therapeutic option for the COVID-19. Travel Med Infect Dis. 2020; 34: 101615

30. Wang M, Cao R, Zhang L, Yang X, Liu J, Xu M et al. Remdesivir and chloroquine effectively inhibit the recently emerged novel coronavirus (2019-nCoV) in vitro. Cell Res. 2020; 30: 269-271.

31. Cao YC, Deng QX, Dai SX. Remdesivir for severe acute respiratory syndrome coronavirus 2 causing COVID-19: an evaluation of the evidence. Travel Med Infect Dis. 2020; 35: 101647.

32. Grein J, Ohmagari N, Shin D, Diaz G, Asperges E, Castagna A et al. Compassionate use of remdesivir for patients with severe COVID-19. N Engl J Med. 2020; 382 (24): 2327-2336.

33. Bhatraju PK, Ghassemieh BJ, Nichols M, Kim R, Jerome KR, Nalla AK et al. COVID-19 in critically ill patients in the Seattle region - case series. N Engl J Med. 2020; 382 (21): 2012-2022.

34. Wang Y, Zhang D, Du G, Du R, Zhao J, Jin Y et al. Remdesivir in adults with severe COVID-19: a randomised, double-blind, placebo-controlled, multicentre trial. Lancet. 2020; 395 (10236): 1569-1578.

35. Furuta $\mathrm{Y}$, Komeno $\mathrm{T}$, Nakamura T. Favipiravir (T-705), a broad spectrum inhibitor of viral RNA polymerase. Proc Jpn Acad Ser B Phys Biol Sci. 2017; 93: 449-463.

36. Sissoko D, Laouenan C, Folkesson E, M'Lebing AB, Beavogui $\mathrm{AH}$, Baize $\mathrm{S}$ et al. Experimental treatment with favipiravir for Ebola virus disease (the JIKI trial): a historically controlled, single-arm proof-of-concept trial in Guinea. PLoS Med. 2016; 13: e1001967.

37. Cai Q, Yang M, Liu D, Chen J, Shu D, Xia J et al. Experimental treatment with favipiravir for COVID-19: an open-label control study. Engineering (Beijing). 2020.

38. Chen C, Huang J, Cheng Z, Wu J, Chen S, Zhang $Y$ et al. Favipiravir versus arbidol for COVID-19: a randomized clinical trial. medRxiv. 2020.
39. Irie $\mathrm{K}$, Nakagawa A, Fujita $\mathrm{H}$, Tamura $\mathrm{R}$, Eto $\mathrm{M}$, Ikesue $\mathrm{H}$ et al. Pharmacokinetics of favipiravir in critically ill patients with COVID-19. Clin Transl Sci. 2020:10.1111/cts.12827.

40. Cvetkovic RS, Goa KL. Lopinavir/ritonavir: a review of its use in the management of HIV infection. Drugs 2003; 63: 769-802.

41. Chu CM, Cheng VC, Hung IF, Wong MM, Chan KH, Chan KS et al. Role of lopinavir/ritonavir in the treatment of SARS: initial virological and clinical findings. Thorax. 2004, 59: 252-256.

42. Chan KS, Lai ST, Chu CM, Tsui E, Tam CY, Wong MM et al. Treatment of severe acute respiratory syndrome with lopinavir/ ritonavir: a multicentre retrospective matched cohort study. Hong Kong Med J 2003; 9: 399-406.

43. Chinese Clinical Guidance for COVID-19 Pneumonia Diagnosis and Treatment (7th edition). [Accessed March 22 2020] Available in: http://kjfy.meetingchina.org/msite/news/show/cn/3337.html..

44. Cao B, Wang Y, Wen D, Liu W, Wang J, Fan G et al. A trial of lopinavir-ritonavir in adults hospitalized with severe COVID-19. N Engl J Med. 2020; 382: 1787-1799.

45. Schoergenhofer C, Jilma B, Stimpfl T, Karolyi M, Zoufaly A. Pharmacokinetics of lopinavir and ritonavir in patients hospitalized with coronavirus disease 2019 (COVID-19). Ann Intern Med. 2020; M20-1550.

46. Hung IF, Lung KC, Tso EY, Liu R, Chung TW, Chu MY et al. Triple combination of interferon beta- $1 \mathrm{~b}$, lopinavir-ritonavir, and ribavirin in the treatment of patients admitted to hospital with COVID-19: an open-label, randomised, phase 2 trial. Lancet. 2020; 395: 1695-1704.

47. Arabi YM, Shalhoub S, Mandourah Y, Al-Hameed F, Al-Omari A, Al Qasim E et al. Ribavirin and interferon therapy for critically ill patients with middle east respiratory syndrome: a multicenter observational study. Clin Infect Dis. 2020; 70: 1837-1844.

48. Song $Y$, Zhang M, Yin L, Wang $K$, Zhou $Y$, Zhou $M$ et al. COVID-19 treatment: close to a cure? A rapid review of pharmacotherapies for the novel coronavirus (SARS-CoV-2). Int J Antimicrob Agents. 2020; 106080.

49. Zhang J, Zhou L, Yang Y, Peng W, Wang W, Chen X. Therapeutic and triage strategies for 2019 novel coronavirus disease in fever clinics. Lancet Respir Med. 2020, 8: e11-e12.

50. Lian N, Xie H, Lin S, Huang J, Zhao J, Lin Q. Umifenovir treatment is not associated with improved outcomes in patients with coronavirus disease 2019: a retrospective study. Clin Microbiol Infect. 2020; 26: 917-921.

51. Wang BX, Fish EN. Global virus outbreaks: Interferons as 1st responders. Semin Immunol. 2019; 43: 101300.

52. Zhou Q, Chen V, Shannon CP, Wei XS, Xiang X, Wang X et al. Interferon-alpha2b treatment for COVID-19. Front Immunol. 2020; 11: 1061 .

53. Chen G, Wu D, Guo W, Cao Y, Huang D, Wang H et al. Clinical and immunological features of severe and moderate coronavirus disease 2019. J Clin Invest. 2020, 130: 2620-2629.

54. Panel. C-TG. Coronavirus disease 2019 (COVID-19) treatment guidelines. National Institutes of Health. [Accessed July 17th, 2020] Available at: https://http://www. covid19treatmentguidelines.nih.gov/.

55. Crisafulli S, Isgro V, La Corte L, Atzeni F, Trifiro G. Potential role of anti-interleukin (IL)-6 drugs in the treatment of COVID-19: rationale, clinical evidence and risks. BioDrugs. 2020;

56. Zhang C, Wu Z, Li JW, Zhao H, Wang GQ. Cytokine release syndrome in severe COVID-19: interleukin-6 receptor antagonist tocilizumab may be the key to reduce mortality. Int J Antimicrob Agents. 2020; 55: 105954.

57. Sciascia S, Apra F, Baffa A, Baldovino S, Boaro D, Boero R et al. Pilot prospective open, single-arm multicentre study on off-label 
use of tocilizumab in patients with severe COVID-19. Clin Exp Rheumatol. 2020; 38: 529-532.

58. Xu X, Han M, Li T, Sun W, Wang D, Fu B et al. Effective treatment of severe COVID-19 patients with tocilizumab. Proc Natl Acad Sci USA. 2020; 117: 10970-10975.

59. Luo P, Liu Y, Qiu L, Liu X, Liu D, Li J. Tocilizumab treatment in COVID-19: a single center experience. J Med Virol. 2020; 92 : 814-818.

60. Toniati P, Piva S, Cattalini M, Garrafa E, Regola F, Castelli F et al. Tocilizumab for the treatment of severe COVID-19 pneumonia with hyperinflammatory syndrome and acute respiratory failure: a single center study of 100 patients in Brescia, Italy. Autoimmun Rev. 2020; 19: 102568.

61. Benucci M, Giannasi G, Cecchini P, Gobbi FL, Damiani A, Grossi V et al. COVID-19 pneumonia treated with sarilumab: a clinical series of eight patients. J Med Virol. 2020; 10.1002/ jmv.26062.

62. Della-Torre E, Campochiaro C, Cavalli G, De Luca G, Napolitano A, La Marca S et al. Interleukin-6 blockade with sarilumab in severe COVID-19 pneumonia with systemic hyperinflammation: an open-label cohort study. Ann Rheum Dis. 2020; annrheumdis-2020-218122.

63. Palanques-Pastor T, Lopez-Briz E, Poveda Andres JL. Involvement of interleukin 6 in SARS-CoV-2 infection: siltuximab as a therapeutic option against COVID-19. Eur J Hosp Pharm. 2020; ejhpharm-2020-002322.

64. Cavalli G, De Luca G, Campochiaro C, Della-Torre E, Ripa M, Canetti $D$ et al. Interleukin-1 blockade with high-dose anakinra in patients with COVID-19, acute respiratory distress syndrome, and hyperinflammation: a retrospective cohort study. Lancet Rheumatol. 2020; 2: e325-e331.

65. Stockman LJ, Bellamy R, Garner P. SARS: systematic review of treatment effects. PLoS Med. 2006; 3: e343.

66. Arabi YM, Mandourah Y, Al-Hameed F, Sindi AA, Almekhlafi GA, Hussein MA et al. Corticosteroid therapy for critically ill patients with middle east respiratory syndrome. Am J Respir Crit Care Med. 2018; 197: 757-767.

67. Rodrigo C, Leonardi-Bee J, Nguyen-Van-Tam J, Lim WS. Corticosteroids as adjunctive therapy in the treatment of influenza. Cochrane Database Syst Rev. 2016; 3: CD010406.

68. Chen N, Zhou M, Dong X, Qu J, Gong F, Han Y et al. Epidemiological and clinical characteristics of 99 cases of 2019 novel coronavirus pneumonia in Wuhan, China: a descriptive study. Lancet. 2020; 395: 507-513.

69. Wu C, Chen X, Cai Y, Xia J, Zhou X, Xu S et al. Risk factors associated with acute respiratory distress syndrome and death in patients with coronavirus disease 2019 pneumonia in Wuhan, China. JAMA Intern Med. 2020; 180 (7): 1-11.

70. Yang Z, Liu J, Zhou Y, Zhao X, Zhao Q, Liu J. The effect of corticosteroid treatment on patients with coronavirus infection: a systematic review and meta-analysis. J Infect. 2020; 81: e13-e20.

71. Group RC, Horby P, Lim WS, Emberson JR, Mafham M, Bell JL et al. Dexamethasone in hospitalized patients with COVID-19preliminary report. N Engl J Med. 2020.

72. Perez EE, Orange JS, Bonilla F, Chinen J, Chinn IK, Dorsey M et al. Update on the use of immunoglobulin in human disease: $\mathrm{A}$ review of evidence. J Allergy Clin Immunol. 2017; 139: S1-S46.

73. Sakoulas G, Geriak M, Kullar R, Greenwood K, Habib M, Vyas A et al. Intravenous immunoglobulin (IVIG) significantly reduces respiratory morbidity in COVID-19 pneumonia: a prospective randomized trial. medRxiv 2020.07.20.20157891; doi: https:// doi.org/10.1101/2020.07.20.201578912020.
74. Shao Z, Feng Y, Zhong L, Xie Q, Lei M, Liu Z et al. Clinical efficacy of intravenous immunoglobulin therapy in critical patients with COVID-19: A multicenter retrospective cohort study. medRxiv. 2020; Preprint. Available at: https://http://www. medrxiv.org/content/10.1101/2020.04.11.20061739v2. 2020.

75. Luke TC, Kilbane EM, Jackson JL, Hoffman SL. Meta-analysis: convalescent blood products for Spanish influenza pneumonia: a future H5N1 treatment? Ann Intern Med. 2006; 145: 599-609.

76. Mair-Jenkins J, Saavedra-Campos M, Baillie JK, Cleary P, Khaw FM, Lim WS et al. The effectiveness of convalescent plasma and hyperimmune immunoglobulin for the treatment of severe acute respiratory infections of viral etiology: a systematic review and exploratory meta-analysis. J Infect Dis. 2015; 211: 80-90.

77. Cheng Y, Wong R, Soo YO, Wong WS, Lee CK, Ng MH et al. Use of convalescent plasma therapy in SARS patients in Hong Kong. Eur J Clin Microbiol Infect Dis. 2005; 24: 44-46.

78. Wang $X$, Guo $X$, Xin Q, Pan Y, Hu Y, Li J et al. Neutralizing antibodies responses to SARS-CoV-2 in COVID-19 inpatients and convalescent patients. Clin Infect Dis. 2020; ciaa721.

79. Li L, Zhang W, Hu Y, Tong X, Zheng S, Yang J et al. Effect of convalescent plasma therapy on time to clinical improvement in patients with severe and life-threatening COVID-19: a randomized clinical trial. JAMA. 2020; e2010044.

80. Liu ST, Lin HM, Baine I, Wajnberg A, Gumprecht JP, Rahman $F$ et al. Convalescent plasma treatment of severe COVID-19: a matched control study. medRxiv. 2020; Preprint. Available at: https://http://www.medrxiv.org/content/10.1101/2020.05.20.201 02236v1. 2020.

81. Salazar E, Perez KK, Ashraf M, Chen J, Castillo B, Christensen PA et al. Treatment of coronavirus disease 2019 (COVID-19) patients with convalescent plasma. Am J Pathol. 2020; 190: 1680-1690.

82. Olivares-Gazca JC, Priesca-Marin JM, Ojeda-Laguna M, Garces-Eisele J, Soto-Olvera S, Palacios-Alonso A et al. Infusion of convalescent plasma is associated with clinical improvement in critically ill patients with COVID-19: a pilot study. Rev Invest Clin. 2020; 72: 159-164.

83. Ye M, Fu D, Ren Y, Wang F, Wang D, Zhang F et al. Treatment with convalescent plasma for COVID-19 patients in Wuhan, China. J Med Virol. J Med Virol. 2020; 10.1002/jmv.25882.

84. Zeng QL, Yu ZJ, Gou JJ, Li GM, Ma SH, Zhang GF et al. Effect of convalescent plasma therapy on viral shedding and survival in patients with coronavirus disease 2019. J Infect Dis. 2020; 222 : 38-43.

85. Joyner MJ, Wright RS, Fairweather D, Senefeld JW, Bruno KA, Klassen SA et al. Early safety indicators of COVID-19 convalescent plasma in 5,000 patients. J Clin Invest. 2020;

86. Mancia G, Rea F, Ludergnani M, Apolone G, Corrao G. Reninangiotensin-aldosterone system blockers and the risk of COVID-19. N Engl J Med. 2020;

87. Reynolds HR, Adhikari S, Pulgarin C, Troxel AB, Iturrate E, Johnson SB et al. Renin-angiotensin-aldosterone system inhibitors and risk of COVID-19. N Engl J Med. 2020; 382 (25): 2441-2448.

88. Mehra MR, Desai SS, Kuy S, Henry TD, Patel AN. Cardiovascular disease, drug therapy, and mortality in COVID-19. N Engl J Med. 2020; 382 (25): e102.

89. Flacco ME, Acuti Martellucci C, Bravi F, Parruti G, Cappadona $\mathrm{R}$, Mascitelli A et al. Treatment with ACE inhibitors or ARBs and risk of severe/lethal COVID-19: a meta-analysis. Heart. 2020;

90. Grover A, Oberoi M. A systematic review and meta-analysis to evaluate the clinical outcomes in COVID-19 patients on angiotensin-converting enzyme inhibitors or angiotensin 
receptor blockers. Eur Heart J Cardiovasc Pharmacother. 2020; pvaa064.

91. Pirola CJ, Sookoian S. Estimation of renin-angiotensinaldosterone-system (RAAS)-inhibitor effect on COVID-19 outcome: a meta-analysis. J Infect. 2020; 81 (2): 276-281.

92. Verdecchia PC, Spanevello C, Angeli A, F. The pivotal link between ACE2 deficiency and SARSCoV-2 infection. Eur J Intern Med. 2020; 76: 14-20.

93. Brogi SC, V. Off-target ACE2 ligands: possible therapeutic option for CoVid-19? Br J Clin Pharmacol. 2020; ; 86 (6): 11781179.

94. Kulemina LV, Ostrov DA. Prediction of off-target effects on angiotensin-converting enzyme 2. J Biomol Screen. 2011; 16: 878-885.

95. Benedetti CWM, Zaza G, Riella LV, Cravedi P. COVID-19 and the kidneys: an update. Front Med. 020-06-30. | https://doi. org/10.3389/fmed.2020.00423.
96. Rizk JG, Kalantar-Zadeh K, Mehra MR, Lavie CJ, Rizk Y, Forthal DN. Pharmaco-immunomodulatory therapy in COVID-19. Drugs. 2020.

97. https://http://www.covid19-druginteractions.org/ Last Update: $9 / 04 / 2020$.

Correspondencia:

Dr. Luis E. Morales Buenrostro

Área de Nefrología del Trasplante. Departamento de Nefrología y Metabolismo Mineral. Instituto Nacional de Ciencias Médicas y Nutrición «Salvador Zubirán».

Vasco de Quiroga 15, Belisario Domínguez Sección XVI, Tlalpan, CDMX, CP 14080

E-mail: luis_buenrostro@yahoo.com 